\title{
内頸動脈瘤手術時の動脈損傷の対処
}

\author{
谷中 清之, 岡崎 匡雄, 鯨岡 裕司 \\ 目黑 琴生, 松丸 祐司, 塚田 篤郎 \\ 淺川 弘之, 上村 和也, 能勢 忠男
}

\section{Repair of a Tear at the Base of an Aneurysm During Microsurgical Clipping of Ruptured Cerebral Aneurysm}

\author{
Kiyoyuki Yanaka, M.D., Masao OKaZAKI, M.D., Yuji KuJIRAOKa, M.D., \\ Kotoo Meguro, M.D., Yuji Matsumaru, M.D., Atsuro Tsukada, M.D., \\ Hiroyuki Asakawa, M.D., Kazuya Uemura, M.D., and Tadao Nose, M.D. \\ Department of Neurosurgery, Institute of Clinical Medicine, University of Tsukuba, Tsukuba, \\ Ibaraki, Japan
}

Summary: Aneurysms can produce large defects in the parent vessel if the aneurysm tears at the neck of the vessel. We present techniques used to repair a tear at the base of an aneurysm encountered during microsurgical clipping of a ruptured aneurysm.

The repair technique involved suturing and covering the aneurysm with an encircling aneurysm clip. A large tear had destroyed the vessel's tubular structure and therefore an encircling clip alone was insufficient for repair. Two microsuture stitches were placed on the tear, so that a split artery reformed a tubular structure. The temporary clip on the distal internal carotid artery was removed for a moment, allowing the retrograde blood flow to provide the counterforce necessary to maintain the vessel's tubular structure.

An encircling clip was then applied to cover the entire circumference of the lesion. Another technique involved placing needles over a tear and applying clips while avoiding parent artery stenosis. Placing a clip to cover an entire tear resulted in an arterial stenosis but just applying a clip was insufficient for repair. With this guiding needle method, a clip can adequately be placed without parent artery stenosis.

These methods required only a short occlusion time for arterial repair, thus helping avoid ischemic complications. These techniques are useful for repairing an aneurysmal tear at its base, especially if the tear is large.

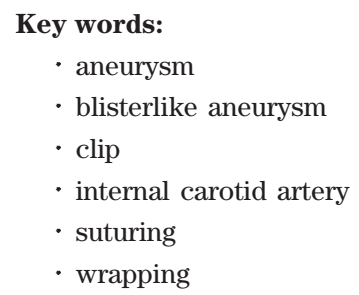

Surg Cereb Stroke (Jpn) 31: 24-28, 2003
はじめに

脳動脈瘤のタリッピング時に，脳動脈瘤の頸部断裂などを損傷してしまう場合がある。そのさいにはしばしば親動 脳神経外科(受稿日 2002.7.24)〔連絡先： $=305-8575$ 茨城県つくば市大王台 $1^{-1} 1^{-1}$ 筑波大学臨床医学系 䑈神経 外科 谷中清之] [Mailing address: Kiyoyuki Y ANAKA, M.D., D epartment of Neurosurgery, Institute of Clinical Medicine, University of Tsukuba, 1-1-1 Tennodai, Tsukuba, Ibaraki 305-8575, Japan] 

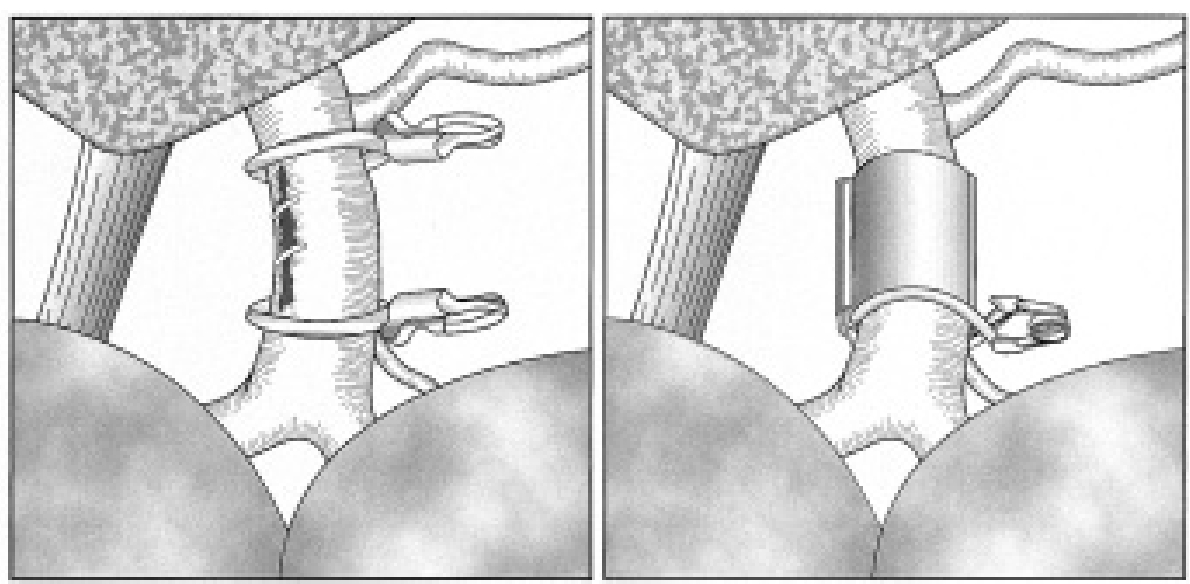

Fig. 1 Schematic presentation of repairing arterial tear at the base of a blisterlike aneurysm arising from the anteromedial wall of the internal carotid artery. A: Two temporary clips are applied to control bleeding. Then nylon suture is put just twice on the tear so that split artery reforms tubular structure. B: An encircling clip is placed to reinforce the entire lesion.

\section{A $\mid \mathbf{B}$}

脈閉塞などが避けられなくなり，重大な虚血合併症を招く。 われわれは過去 5 年間に 2 例のクリッピング時の内顁動脈 損傷を経験した。1 例は石灰化が強い内頸動脈-後交通動 脈分岐部動脈瘤であり，他方は内㘔動脈背侧部動脈瘤であ る。背側部動脈瘤に対する対処に関してはすでに発表して 扔り，本稿では簡単に紹介するにとどめるが21)，自験例 を基に動脈損傷時の修復法について，若干の文献的考察を 加えて検討する。

\section{症例}

〈症例 1〉46歳女性で, くも膜下出血で発症した。来院 時 Hunt \& Hess Grade 3 であった. 脳血管撮影の結果, 右内頚動脈背側部動脈瘁を認めた。手術では薄いフィブリ ン様被膜で覆われた動脈瘤を認めた。タリップで動脈瘤頸 部を挟むも，タリップごと瘤が吹き飛び，内頸動脈壁に大 きな損傷部ができた。この損傷部を Suturing \& Encircling clip 法で修復し良好な予後を得た。本法に関し てはすでに発表して扮り ${ }^{21)}$ ，穴の手法を以下に簡単に記 す。(1)内頸動脈に平行にタリッピングを施行後, 動脈瘤頙 部からタリップごと壁損傷が発生した。(2)損傷部の近位・ 遠位部に temporary clip を㧍き- 時的に血流を遮断した。 (3) 2 針のみ内頸動脈壁に糸をかけ管腔構造を作成した. (4) サージセルをわずかに置いて損傷部を軽く塞いだのち，遠 位部の temporary clipのみ開放した。(5)逆行性の血流に より内䫫動脈は膨らみ，その後ただちにencircling clipt 扔くと, clipに対し逆行性の血圧がかかって修復が可能と なったにのさい近位部のclip を先にはずすと，高圧で損 傷部のサージセルがとんでしまう)。(6)最後に近位のtemporary clipをはずし, 修復を終〕した (Fig. 1)。術中・術
後の脳血管撮影では, 内镇動脈の patency は保たれ，患者 は一過性の上肢に強い麻疩を呈したがすみやかに回復し た。術後半年の CTでは新なな脳棵塞巣の出現は認められ なかった。

本手技の要点は, 遮断時間短縮のため糸をかける回数を 少なくすることと, temporary clipのはずす順番を遠位側 から行うことである。

〈症例 2〉76歳女性で, くも膜下出血で発症した。来院 時 Hunt \& Hess Grade 2 であった。脳血管撮影の結果, 右内頙動脈一後交通動脈分岐部動脈瘤を認めた。血管撮影 上，動脈硬化は著明で， CT上も動脈瘤周目に石灰化が疑 われた。

クリッピング術を施行した。タリップで動脈瘤镇部を挟 むも，頸部が石灰化のため堅く，十分にタリップの先端が 閉じない状況であった。長めのクリップなど挟力の強いク リップで陚行錯誤を繰り返しているうちに動脈瘤貿部が裂 け，内頸動脈壁に線状の損傷をきたした，損傷部の裏侧か らは太い穿通枝が出ていた。

この損傷部を修復するため，曲がりのついたタリップで 穴を塞ぐようにタリップを置いた。内頸動脈に狭乍を作ら 奴ようクリップをおくと，損傷部が完全に覆えず不十分な 修復となり，損傷部を完全に塞ごうとすると内镇動脈が狹 窄してしまい，最適なところでクリップを置くことに難渋 した。内頸動脈侧にタリップを押しつけると内頸動脈が狭 窄し, 押しつけないと損傷部が塞がらない状況であった。 本例では，6-0ナイロン糸の針を用いてクリップのガイデ インダを行い, 適切な位置にタリップを置くことができた。 すなわち，(1)糸を切り離した針を 2 箇所損傷部ぎりぎりに 通した。(2)この針をすくうようにして，タリップを内頸動 

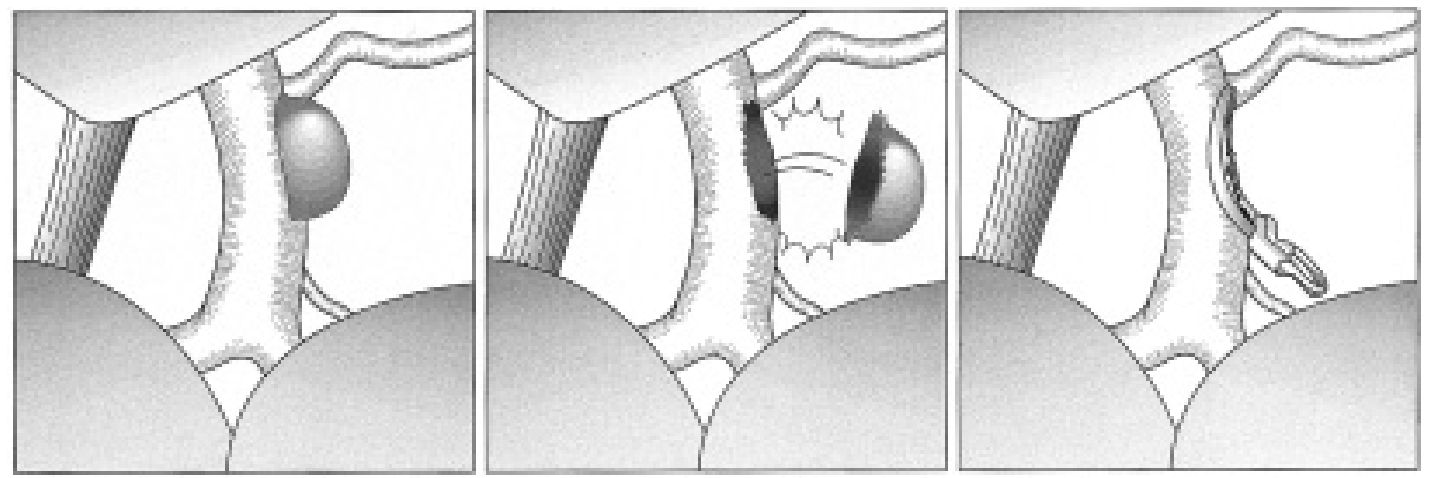

Fig. 2 Schematic presentation of repairing arterial tear at the base of a saccular aneurysm arising from the posteromedial wall of the internal carotid artery. A: An aneurysm is seen on the posteromedial wall of the internal carotid artery. B: The aneurysm is separated from its base. C: A curved clip is placed.
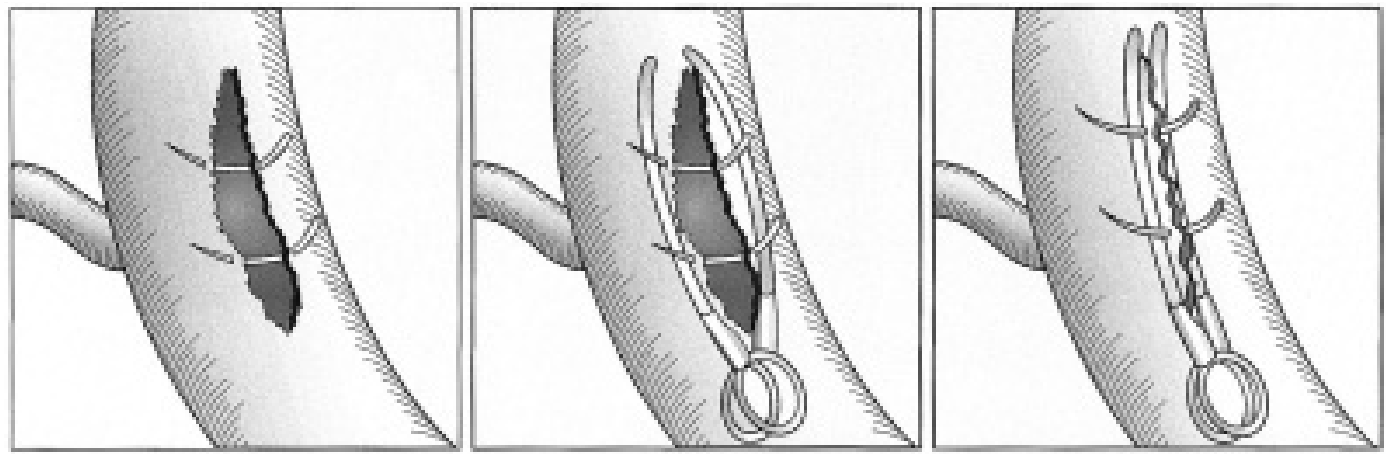

Fig. 3 Schematic presentation of repairing arterial tear with needle-guiding technique. A: Two curved needles are placed just periphery of a tear. B, C: Lifting the guiding needle to avoid arterial stenosis, a clip is placed adequately. Needles are removed after putting a clip.

眽から離す方向に力を加えつつ，損傷部全体を挟んだ。そ の後ガイドにしていた針を抜去した。これによって内頸動 脈の狭窄は最小限で抑えられた(Fig. 2,3)。

術中血管撮影では，内頸動脈の patencyは良好に保たれ て抢り，特に神経脱落兆候なく退院となった。術後半年の CTでは新たな脳㭺塞巣の出現は認められなかった。

\section{考察}

血管損傷は末梢部への血流途絶をきたし局所症状を招く ため，是非とも避けねばならない，脳主幹動脈においては 灌流域も広くその損傷は重大な予後不良因了となる。こと に内頸動脈は, 流量も多く深部に位置し, 損傷時の対処が 困難である。また，この部には背侧部動脈瘤などの壁の脆 弱な動脈瘤も発生し ${ }^{1110)}$, さらに比較的径の大きな動脈瘤 も発生しやすい，大きな動脈瘤では頸部も大きく，また瘤 自体の剝離も不十分となりやすく, クリッピング時に頚部 に剪断力などのストレスがかかりやすい。本来䫓部で動脈 瘤が破裂する場合は全体の $2 \%$ 程度にすぎず 16), 頸部自
体が脆弱である場合は少ない。われわれの 2 症例は，背側 部動脈瘤で壁が非常に脆弱であったものと，石灰化が強く 頸部自体が堅く(そして多分脆く), タリップのかけ直し のさいにストレスが働き損傷に至ったものと考えられた。

血管損傷部の修復には, 損傷の程度によって適切な方法 を選ぶ必要がある。内钼動脈背侧部動脈瘤は, 通常の褰状 (saccular) 動脈瘤とチマメ状 (blisterlike) 動脈瘤の 2 種類 に分類でき ${ }^{11)}$, distal medial wall an eurysms ${ }^{22)}$, dorsal ICA aneurysms ${ }^{10)}$, superior wall of the ICA aneurysms ${ }^{6)}$, internal carotid artery trunk aneurysms ${ }^{11)}$ な ど種々の名称で呼ばれている。このうち，チマメ状脳動脈 瘤は，通常の脳動脈瘤と異なり血管の分岐部と関係なく発 生し，しっかりとした壁を持たずに結合織やフィブリンで

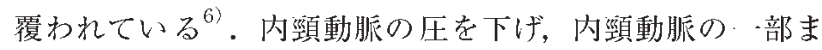
ですくうようにクリップをかけ成功した症例も報告されて いるが5 ${ }^{5}$, 血管壁の解離性変化の関与により動脈瘤近傍の 血管壁も異常であり，タリッピングを施行すること自体禁 忌とする考えもある゙〉。われわれも，いったんクリップを 
留置したものの, 数造して再び同部が増大し, 治療に難涉 した症例を経験した。タリップのみで対処できれば最善で あるが, 損傷部の血管の状況など注意深く確認し, 適切な 対処法を考えることが重要である.

われわれは脳動脈瘤の手術のさい，ほぼ全例で術中血管 撮影を行い, 脳動脈瘤の消失と親動脈の狭窄や閉塞がない

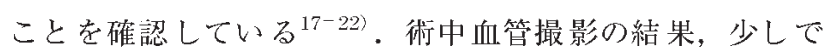
も狭窄があると思われた場合, 放置すると多くの例で術後 の虚血合併症を抬く，背侧部動脈瘤において確実なクリッ ピングのためには，動脈壁をより広い範囲でクリップする 必要があると思わ机, 虚血合併症の可能性も高くなる。 こでラッピングなどの方法が考案された(3)6/7)9)13/24). ラ ッピング法を用いた脳動脤瘤の治療経験が種々報告されて いるが，その成績はまちまちであり，予後不良の場合は血 流遮断に基づく虚血合併症による1)4111) 12)14)15)23)。われ われの用いた suturing \& encircling 法は, 管腔構造を作 るためだけのわずか 1,2 針にとどめるため, 完全に縫合 するのに比べ血流遮断時間が短時間で済み, 虚血合併症の 危険性を小さくできる。しかしながら, 深部の操作であり 熟練が必要であり。単純に 1 個のクリップで動脈瘤の処置 ができればそれが最善である。親動脈に狭窄をきたすよう な可能性のある場合, 術中血管撮影などで親動脈に十分な patencyがあることを確認すべきであろう。

また血管損傷が線状で，1個のクリップを用いて・期的 に修復が可能にみえる場合でも，親動脈に狭窄をきたさな いよう心がける必要がある。午のさいに有効なのが症例 2 で用いた縫合針によるクリップのガイディングである。縫 合針によって損傷部を縫合する方法も紹介されている が5), 縫合のみで対処しようとするとかなり密に縫わ稀ば ならず，虚血時間が長くなる可能性がある。それに対して ガイディング法では単に針を置くだけであるので, 時間的 には短くてすむ。また損傷部の近傍に穿通枝などがあると encircling clip では対処できないが, 本法では可能であり, 親動脈の狭窄が最小にできる。

これらの修復技法は，損傷部の大きさに応じて使い分け る必要があるが, 損傷部位が大きすぎたり，血管の裹侧に 位置していたりした場合には適応できない。また前眽絡巣 動脈や重要な穿通枝が裏侧から出ている場合にも suturing \& encircling 法は適応できない。われわれはたまたま幸運 に恵まれたため修復できただけで，この 2 つの手法によっ て修復できない場合のほうが多いのかもしれない.しかし， 常に最患の場合を想定し, 瘤の近位部の確実な確保, 深部 用の持針器や $\operatorname{Vascwrap}^{8}$ など特殊な手術器其の常備, そ して本法のような工夫や, 親動脈閉塞とバイパス術の併用 などができるかどうかの冷静な判断が重要である.

\section{文献}

1) Abe M, Tabuchi $\mathrm{K}$, Yokoyama $\mathrm{H}$, et al: Blood blisterlike aneurysms of the internal carotid artery. J Neurosurg 89: 419-424, 1998

2) Cromptom MR: Mechanism and growth and rupture in cerebral berry aneurysms. $\mathrm{Br}$ Med J 1: 1138-1142, 1966

3) Heifetz MD: A new intracranial aneurysm clip. Technical suggestion, J Neurosurg 30: 753, 1969

4）本郷和広, 新田純平, 小林茂昭, ほか：術中タリッピンダ からラッピングへの变更を余義なくされた内頸動脈破裂背 側動脈瘤の 1 例。脳卒巾の外科 30: 159-163, 2002

5）石川達哉, 上山博康, 数又研, ほか：到部で裂けやすい 動脈瘤, 頚部で裂けた時の処置一動脈瘤手術の pitfall一. 脳卒中の外科 $30: 153-158,2002$

6) Ishikawa T, Nakamura N, Houkin K, et al: Pathological consideration of a "blister-like" aneurysm at the superior wall of the internal carotid artery: case report. Neurosurgery 40: 403-406, 1997

7) Ishiwata $\mathrm{Y}$, Inamori S, Fujitsu K, et al: A new intracranial Silastic encircling clip for hemostasis Technical note. J Neurosurg 73: 638-639, 1990

8) Kawase T, Gotoh K, Toya S: A wrapping clip combined with silastic sheet for emergent hemostasis: technical note. Neurosurgery 35: 769-771, 1994

9) Lanzino G, diPierro CG, Laws ER: Sutureless repair of major intracranial vessels with the Sundt clip-graft: technical note. Acta Neurochir (Wien) 140: 491-493, 1998

10) Nakagawa F, Kobayashi S, Takemae T, et al: Aneurysms protruding from the dorsal wall of the internal carotid artery. J Neurosurg 65: 303-308, 1986

11) Ogawa A, Suzuki M, Ogasawara K: A neurysms at nonbranching sites in the supraclinoid portion of the internal carotid artery: internal carotid artery trunk aneurysms. Neurosurgery 47: 578-586, 2000

12) Ogilvy CS: Repair of an arterial perforation of the internal carotid artery using Hemashield wrapping with aneurysm clip reinforcement: technical note. Neurosurgery 40: $1312-1314,1997$

13) Sundt TM Jr., Nofzingger JD: Clip-grafts for aneurysm and small vessel surgery. Part 1: Repair of segmental defects with clip-grafts; laboratory studies and clinical correlations. Part 2: Clinical application of clip-grafts to aneurysms technical considerations. J Neurosurg 27: 477 489, 1967

14）竹下幹彦, 恩田英明, 谷川達也, ほか：頭蓋内内到動脈前 壁動脈瘤の臨床的検討. 脳卒巾の外科 25: 134-139, 1997

15）渡辺伸一，加藤甫子，佐野公俊，ほ活：IC blister-like aneurysm に対する治療法Clipping on wrapping method 及 びGORE-TEX wrap clipの利用. 脳卒巾の外科 25: 53-58, 1997

16) Weir B, Macdonald RL: Intracranial aneurysms and subarachnoid hemorrhage: an overview, in Wilkins $\mathrm{RH}$, Rengachary SS (eds): Neurosurgery, 2nd ed, Volume 2, McGraw-Hill, New York, 1996, pp2191-2213

17) Yanaka $\mathrm{K}$, Asakawa $\mathrm{H}$, Noguchi $\mathrm{S}$, et al: Intraoperative angiography evaluation of the microsurgical clipping of unruptured cerebral aneurysms. Neurol Med Chir 42: 193-201, 2002

18) Yanaka K, Matsumaru $Y$, Kamezaki $T$, et al: Ruptured aneurysm of the ophthalmic artery trunk demonstrated by three-dimensional rotational angiography. Case report. 
Neurosurgery 51: 1066-1069, 2002

19) Yanaka $K$, Meguro $K$, Narushima $K$, et al: Basal perforating artery aneurysm within the cavum septi pellucidi. J Neurosurg 88: 601-604, 1998

20) Yanaka $K$, Meguro $K$, Nose T: Intraoperative angiography. J Neurosurg 89: 501-502, 1998

21) Yanaka K, Meguro K, Nose T: Repair of a tear at the base of a blisterlike aneurysm with suturing and encircling clip. Technical note. Neurosurgery 50: 218-221, 2002
22) Yanaka K, Tsuboi K, Fujita K, et al: Distal anterior choroidal artery aneurysm associated with an arteriovenous malformation. Intraoperative localization and treatment. Surg Neurol 53: 546-551, 2000

23) Yasargil MG: Microneurosurgery, Vol 2. Stuttgart George Thieme Verlag, 1984, pp58-59

24) Yokoo A, Sugita K, Kobayashi S, et al: A simple hemostatic method using a metal shield for injury of a major cerebral artery. J Neurosurg 57: 323-327, 1982 